\title{
Long Non-Coding RNA PVT1/miR-150/ HIG2 Axis Regulates the Proliferation, Invasion and the Balance of Iron Metabolism of Hepatocellular Carcinoma
}

\author{
Yunxiuxiu Xu $\mathrm{u}^{\mathrm{a}, \mathrm{b}}$ Xinxi Luo $\mathrm{o}^{\mathrm{b}, \mathrm{c}}$ Wenguang He $\mathrm{H}^{\mathrm{d}}$ Guangcheng Chen ${ }^{\mathrm{b}, \mathrm{e}}$ \\ Yanshan Lib,f Wenxin Li ${ }^{a, b} \quad$ Xicheng Wanga, ${ }^{a, b}$ Laib,e Yibiao Ye $e^{a, b}$ \\ aDepartment of Hepato-Billiary Surgery, Sun Yat-sen Memorial Hospital, Sun Yat-sen University, \\ Guangzhou, 'ey Laboratory of Malignant Tumor Gene Regulation and Target Therapy of Guangdong \\ Higher Education Institutes, Sun Yat-sen Memorial Hospital, Sun Yat-sen University, Guangzhou, \\ 'Department of Gastrointestinal Surgery, Sun Yat-sen Memorial Hospital, Sun Yat-sen University, \\ Guangzhou, 'Department of General Surgery, Zengcheng District People's Hospital of Guangzhou, \\ Guangzhou, eDepartment of Gastroenterology, Sun Yat-sen Memorial Hospital, Sun Yat-sen University, \\ Guangzhou, 'Department of Blood Transfusion, Sun Yat-sen Memorial Hospital, Sun Yat-sen University, \\ Guangzhou, China
}

\section{Key Words}

Lnc RNA $・$ PVT1 $・ \mathrm{miR}-150 \cdot \mathrm{HIG} 2 \cdot \mathrm{HCC}$

\begin{abstract}
Background/Aims: To investigate the biological roles and underlying molecular mechanisms of long non-coding RNA (IncRNA) PVT1 in Hepatocellular carcinoma (HCC). Methods: qRTPCR was performed to measure the expression of miRNA and mRNA. Western blot was performed to measure the protein expression. CCK-8 assay was performed to determine cell proliferation. Flow cytometry was performed to detect cell apoptosis. Wounding-healing assay and Transwell assay was performed to detect cell migration and invasion. Dual luciferase reporter assay was performed to verify the target relationship. Quantichrom iron assay was performed to check uptake level of cellular iron. Results: PVT1 expression was up-regulated in HCC tissues and cell lines. Function studies revealed that PVT1 knockdown significantly suppressed cell proliferation, migration and invasion, and induced cell apoptosis in vitro. Furthermore, PVT1 could directly bind to microRNA (miR)-150 and down-regulate miR-150 expression. Hypoxia-inducible protein 2 (HIG2) was found to be one target gene of miR-150, and PVT1 knockdown could inhibit the expression of HIG2 through up-regulating miR-150 expression. In addition, the expression of miR-150 was down-regulated, while the expression of HIG2 was up-regulated in HCC tissues and cell lines. Moreover, inhibition of miR-150 could

Y. Xu, X. Luo and W. He contributed equally to this work.

\begin{tabular}{ll}
\hline Yibiao Ye & Department of Hepato-Billiary Surgery, Sun Yat-sen Memorial Hospital, Sun Yat-sen University \\
& 510120, Guangzhou (China) \\
& E-Mail yeyibiao2018@outlook.com
\end{tabular}
\end{abstract}


partly reverse the biological effects of PVT1 knockdown on proliferation, motility, apoptosis and iron metabolism in vitro, which might be associated with dysregulation of HIG2. In vivo results showed that PVT1 knockdown suppressed tumorigenesis and iron metabolism disorder by regulating the expression of miR-150 and HIG2. Conclusion: Taken together, the present study demonstrates that PVT1/miR-150/HIG2 axis may lead to a better understanding of HCC pathogenesis and provide potential therapeutic targets for HCC.

\section{Introduction}

Hepatocellular carcinoma (HCC) is one of the most common tumors worldwide, and has become the second leading cause of cancer-related death in China [1]. Although great advance in diagnosis and surgical treatment, the recurrence and metastasis rates of HCC are still high. Besides, patients with HCC are usually in advanced stages at their initial diagnosis, and the prognosis of HCC patients with advanced disease remains unsatisfied until now [2]. Despite significant progress in expounding the molecular mechanisms of HCC has been achieved, elucidating the precise regulation underlying liver carcinogenesis still need great efforts. Multiple abnormal molecular expression and disordered signaling pathways are involved in the progression of HCC [3-5]. Recent studies have shown that the regulation of noncoding RNAs (ncRNAs) play a crucial role in HCC, which may contribute to develop new effective therapeutic strategies to improve the prognosis of HCC patients.

Noncoding RNAs (ncRNAs) are defined as non-protein coding RNAs that encompass the well-known microRNAs (miRNAs), as well as the most recently acknowledged long noncoding RNAs (lncRNAs). LncRNAs are transcripts longer than 200 nucleotides that have been demonstrated to manipulate a variety of biological processes, such as proliferation, apoptosis, migration, invasion, tumorigenicity and metastasis, by interacting with multiple molecules including DNA, RNA and proteins [6]. MiRNAs are 18-25 nucleotide long, single-stranded RNAs, which regulate the expression of numerous genes by binding to 3 '-untranslated regions (UTRs) of target mRNAs to induce mRNA degradation or mRNA translation inhibition [7]. In recent years, increasing IncRNAs have been found to play oncogenic or tumor suppressor roles in HCC by regulating miRNAs. Li et al. [8] have demonstrated that the IncRNA-highly up-regulated in liver cancer (HULC) plays as an oncogene in HCC, and enhances epithelialmesenchymal transition (EMT) to promote tumorigenesis and metastasis of HCC via the miR-200a-3p/ZEB1 signaling pathway. Chen et al. [9] have reported that the expression of IncRNA PTENP1 functions as a tumor suppressor in HCC by suppressing the oncogenic PI3K/AKT pathway and regulating miRNAs like miR-17, miR-19b and miR-20a, and thus inhibits cell proliferation, migration, invasion as well as induces autophagy and apoptosis. And those three miRNAs could target PTEN (a tumor suppressor gene), PHLPP (a negative AKT regulator) and autophagy genes, such as ULK1, ATG7 and p62, indicating that lncRNAmiRNA-mRNA axis is deeply involved in modulating the cell behavior and gene networks of HCC.

LncRNA PVT1 is located at 8q24.21, which has been found to be up-regulated in a diverse range of cancers, such as gastric cancer [10], melanoma [11], thyroid cancer [12] and nonsmall cell lung cancer [13]. Recent investigations have revealed that PVT1 was up-regulated in HCC tissues, and the overexpression of PVT1 in HCC patients was closely associated with a poor clinical prognosis. Gain-of-function and loss-of-function experiments have shown that PVT1 promotes cell proliferation, cell cycling, and stem cell-like properties of HCC cells, suggesting that targeting PVT1 may be a potential diagnostic and therapeutic method for HCC $[14,15]$. However, the precise regulation mechanisms of PVT1 signaling in HCC are still largely unknown. MiR-150 has been well studied in many cancers, and its dysregulation is involved in carcinogenesis and cancer progression. Recent studies have demonstrated that miR-150 expression is down-regulated in HCC [16], epithelial ovarian cancer [17] and pancreatic cancer [18], which acts as a tumor suppressor by targeting various genes. 


\section{Cellular Physiology Cell Physiol Biochem 2018;49:1403-1419 \begin{tabular}{l|l} 
DOI: 10.1159/000493445 & $\begin{array}{l}\text { O } 2018 \text { The Author(s). Published by S. Karger AG, Basel } \\
\text { www.karger.com/cpb }\end{array}$
\end{tabular} \\ Xu et al.: PVT1/miR-150/HIG2 Axis Regulates HCC}

However, whether the important roles of PVT1 in HCC are associated with the dysregulation of miR-150 remains unknown.

In the present study, we first investigated the biological effects of PVT1 knockdown on cell proliferation, apoptosis, migration and invasion in HCC. Bioinformatics prediction and experimental analysis confirmed that PVT1 directly targeted miR-150 to regulate its expression, which further targeted the 3'-UTR mRNA of hypoxia-inducible protein 2 (HIG2), one gene related with cell proliferation, apoptosis, iron homeostasis and tumorigenesis. We found that PVT1-miR-150-HIG2 axis was deeply involved in the regulation of cell viability, motility and iron metabolism in HCC in vitro and in vivo.

\section{Materials and Methods}

\section{HCC tissue samples}

A total of 47 paired HCC tissues and corresponding non-cancerous tissues were obtained from patients undergoing routine hepatic resection in Chengdu Military General Hospital. These tissues were snapfrozen in liquid nitrogen after resection immediately, and stored at $-80^{\circ} \mathrm{C}$ prior to the extraction of RNA and protein. This study was approved by the ethics committee of Chengdu Military General Hospital and informed consent was obtained from all patients.

\section{Cell culture}

The normal human hepatic cell line L-02 and 6 HCC cell lines (SK-HEP-1, Hep G2, SMMC-7721, BEL7402, Hep3B2.1-7 and QGY-7703X4) were purchased from American Type Culture Collection. Cells were maintained in Dulbecco's Modified Eagle Medium (DMEM) with $10 \%$ fetal bovine serum, $100 \mathrm{U} / \mathrm{ml}$ penicillin-streptomycin, and cultured in a humidified atmosphere of $5 \% \mathrm{CO}_{2}$ at $37^{\circ} \mathrm{C}$.

\section{Quantitative RT-PCR (qRT-PCR)}

Total RNA were extracted from frozen tissues or cell lines with RNAiso Plus (TaKaRa, Dalian, China) according to the manufacturer's instructions. RNA was reverse transcribed to cDNA by using a Reverse Transcription Kit (Takara). SYBR Premix Ex Taq miRNA kit (TaKaRa) was used to determine the level of miR150, and U6 small nuclear RNA was used as an internal control. SYBR Premix Ex TaqTM II kit (TaKaRa) was used to quantify the expression of PVT1 and HIG2, and GAPDH was used as the reference gene. The relative expression of miR-150, PVT1 and HIG2 were calculated using the $2^{-\Delta \Delta C t}$ method.

\section{Construction of vectors and cell transfection}

To construct PVT1 small interfering (si) RNA vector, the interference oligonucleotides targeting PVT1 were synthesized by GenePharma Co., Ltd. (Shanghai, China), named as PVT1 shRNA. Scrambled oligonucleotides were also synthesized to be used as negative control. The oligonucleotides were annealed into double strands, and were inserted into pGPH1/Neo vector (GenePharma Co., Ltd.). To construct luciferase reporter vectors, the two putative target sites of miR-150 in PVT1 were cloned into psiCkeck2 vector (Promega), named as pPVT1-1 and pPVT1-2. The putative target sites of miR-150 in 3'-UTRs of HIG2 were cloned into psiCkeck2 vector, named as pHIG2. MiR-150 mimic, negative control of mimic (mimic-NC), miR-150 inhibitor and negative control of inhibitor (inhibitor-NC) were ordered from Genechem (Shanghai, China). Vectors and oligonucleotides transfection were all performed by using Lipofectamine ${ }^{\circledR} 2000$ following the manufacturer's instructions (Invitrogen, USA).

\section{Cell proliferation assay}

Cell proliferation was determined by using CCK-8 assay according to the manufacturer's protocol. Briefly, Cells were seeded into 96-well plates and transfected with PVT1 shRNA or shRNA scramble vectors. $10 \mu \mathrm{L}$ CCK-8 solutions were added into each well at particular time points for $4 \mathrm{~h}$ at $37^{\circ} \mathrm{C}$. The absorbance was measured at $450 \mathrm{~nm}$ using a spectrophotometer. 


\section{Cellular Physiology Cell Physiol Biochem 2018;49:1403-1419 \begin{tabular}{l|l|l} 
and Biochemistry & Dublished online: 13 September, 2018 & $\begin{array}{l}\text { (c) } 2018 \text { The Author(s). Published by S. Karger AG, Basel } \\
\text { www.karger.com/cpb }\end{array}$
\end{tabular}}

Xu et al.: PVT1/miR-150/HIG2 Axis Regulates HCC

\section{Cell apoptosis assay}

Cells were seeded into 6-well plates and transfected with PVT1 shRNA or shRNA scramble vectors for $48 \mathrm{~h}$. Then the cells were collected and washed twice with PBS. Thereafter, cells were stained with Annexin V-FITC/PI staining solution in the dark for $15 \mathrm{~min}$, and analyzed using flow cytometry.

\section{Western blot}

Total protein was extracted from tissues and cells by using RIPA protein extraction reagent. The concentrations of total proteins were measured using a BCA protein assay kit. Equal quantities of protein were separated by SDS polyacrylamide gel electrophoresis (SDS-PAGE) and transferred to nitrocellulose membranes. The membranes were blocked with $5 \%$ bovine serum albumin for $1 \mathrm{~h}$ at room temperature, and then were incubated with specific primary antibodies overnight at $4^{\circ} \mathrm{C}$. After being washed, the membranes were incubated with HRP-conjugated anti-IgG at room temperature for $1 \mathrm{~h}$, followed by detection and visualization using an enhanced chemiluminescence (ECL) system. Primary antibodies include anti-Ki67, anti-PCNA, anti-cleaved-caspase-3, anti-cleaved-caspase-9, anti-VEGF, anti-MMP-9, anti-MMP-14, antiVEGFR1, anti-VEGFR2, anti-E-cadherin, anti- N-cadherin, anti-Vimentin, anti-HIG2 and anti-GAPDH was used as control protein.

\section{Cell mobility analysis}

Cell migration and invasion were examined by wound-healing assay and Transwell assay. For woundhealing assay, cells were cultured in 6-well plates and transfected with PVT1 shRNA or shRNA scramble vectors. When the cells were full confluence, the wound was created by scratching cells using $200 \mu \mathrm{L}$ pipette tip and washed twice with fresh medium to remove detached cells. After $24 \mathrm{~h}$ treatments, serial images of cell migration were photographed using an inverted-phase microscope. The rate of wound healing was measured as: ( $0 \mathrm{~h}$ width of wound- $24 \mathrm{~h}$ width of wound $) /(0 \mathrm{~h}$ width of wound). Transwell chambers (8 $\mu \mathrm{m}$ pore size; Millipore) with Matrigel (BD Biosciences) matrix were used to determine cell invasion. One day post-transfection, cells were suspended in serum-free medium, and $200 \mu \mathrm{L}$ cell suspensions $\left(4 \times 10^{4}\right.$ cells $)$ were plated in the top chamber, whereas the lower chambers contained $600 \mu \mathrm{L}$ complete medium. After $24 \mathrm{~h}$, cells on the top surface of the membrane were removed by using a cotton swab. Cells on the bottom surface of the membrane were stained with crystal violet solution, and counted.

\section{Dual luciferase reporter assay}

Cells were seeded in 96-well plates, and were co-transfected with miRNAs (miR-150 mimic, negative control mimic, miR-150 mutant) and pPVT1-1 or pPVT1-2, pHIG2. Forty-eight hours after transfection, dual luciferase reporter assay was used to determine the luciferase activities according to manufacturer's instructions.

\section{Quantitative colorimetric iron assay}

Cellular iron uptake level was detected by Quantichrom iron assay (BioAssay Systems, USA) with reference to the previous study [19]. Briefly, $50 \mu \mathrm{L}$ of standards or samples $\left(10^{6}\right.$ cells $)$ in 96 -well plates were mixed with $200 \mu \mathrm{L}$ Quantichrom Working Reagent, and incubated at room temperature overnight. The optical density (OD) at $590 \mathrm{~nm}$ was measured by a microplate reader.

Then the OD against standard iron concentrations were plotted by subtracting $\mathrm{OD}_{590 \mathrm{~nm}}$ values of blank water $\left(\mathrm{OD}_{\text {blank }}\right)$ from that of standards $\left(\mathrm{OD}_{\text {standard }}\right)$, and the slope of the data plot then determined using liner regression fitting (Slope $=0.0005)$. Iron concentration $\left(\mathrm{IC}_{\text {sample }}\right.$ in $\mu \mathrm{g} / \mathrm{dL}$ ) of the sample can be calculated as: $\mathrm{IC}_{\text {sample }}=\left(\mathrm{OD}_{\text {sample }}-\mathrm{OD}_{\text {blank }}\right) /$ Slope. Given cell concentration $\left(\mathrm{CC}_{\text {sample }}\right)$ in the cell suspension sample of $\mathrm{N}$ (cell/ $\mathrm{dL})\left(\mathrm{N}=10^{6}\right.$ cells $\left./(50 \mu \mathrm{L}+200 \mu \mathrm{L})\right)$, averaged iron uptake per cell (iron uptake in $\left.\mathrm{pg} / \mathrm{cell}\right)$ can be obtained from: IronUptake $=\mathrm{IC}_{\text {sample }} / \mathrm{CC}_{\text {sample }}=\left(\left(\mathrm{OD}_{\text {sample }}-\mathrm{OD}_{\text {blank }}\right) /\right.$ Slope $) \times(1 / \mathrm{N}) \times 10^{6}$.

\section{Animal experiments}

Four-week-old BALB/c male nude mice were purchased from Chengdu Military General Hospital and maintained under specific pathogen-free conditions. HepG2 cells stably transfected with PVT1 shRNA vector or shRNA scramble vector were suspended in $100 \mu \mathrm{L}$ PBS $\left(1 \times 10^{7}\right.$ cells $)$ and subcutaneously injected into the back of each nude mouse. The tumors were measured every 5 days, and all mice were sacrificed to recover the tumors on the 30th day. A portion of the dissected tumors were fixed in $4 \%$ paraformaldehyde 


\section{Cellular Physiology Cell Physiol Biochem 2018;49:1403-1419 \begin{tabular}{ll|l} 
and Biochemistry Published online: 13 September, 2018 & $\begin{array}{l}\text { (c) } 2018 \text { The Author(s). Published by S. Karger AG, Basel } \\
\text { www.karger.com/cpb }\end{array}$ \\
\hline
\end{tabular} \\ Xu et al.: PVT1/miR-150/HIG2 Axis Regulates HCC}

and paraffin-embedded for immunohistochemistry, and another portion were frozen in liquid nitrogen for qRT-PCR and Western blot.

\section{Immunohistochemistry assay}

Tumor tissues were fixed with 4\% paraformaldehyde, dehydrated, embedded in paraffin and sectioned to $4 \mu \mathrm{m}$. The specimens were deparaffinized, hydrated, and boiled in $10 \mathrm{mM}$ citrate buffer (pH 6.0) for antigen retrieval. After blocking in goat serum, the sections were fixed and stained using antibodies against anti-Ki67 and anti-MMP-9 (Biocare Medical, CA, USA) and terminal deoxynucleotidyl transferase dUTP nick-end labeling (TUNEL; BD Pharmingen, CA, USA) assays overnight at $4^{\circ} \mathrm{C}$, and then incubated with biotinylated secondary antibody at room temperature for $1 \mathrm{~h}$, and visualized with diaminobenzidine (DAB) kit (ZSGB-BIO, China). Hematoxylin was used to counterstain the nuclei.

\section{Statistical analysis}

Statistical significance was analyzed by Student's t-test or one-way analysis of variance (ANOVA) using GraphPad Prism 5.0 (GraphPad Prism Software, CA, USA). All results were shown as the means \pm standard error of the mean (SEM) of at least three independent experiments. $P<0.05$ was considered statistically significant.

\section{Results}

Expression of PVT1 was up-regulated in HCC tissues and cell lines

To verify the abnormal expression of PVT1, we performed qRT-PCR assay to determine its expression in 47 pairs of HCC tissues and normal tissues, as well as 6 HCC cell lines and normal human hepatic cell line L-02, respectively. As shown in Fig. 1A, the expression of PVT1 was significantly increased in HCC tissues as compared with that in the normal tissues. Similarly, compare with L-02 cells, the expression of PVT1 in the 6 HCC cell lines, SK-HEP-1, Hep G2, SMMC-7721, BEL-7402, Hep3B2.1-7 and QGY-7703X4, had a marked upregulation, especially in Hep G2 and BEL-7402 cell lines (Fig. 1B). These results confirmed the up-regulation of PVT1 in HCC, reminding us that PVT1 may play an important role in the progression of HCC.

\section{Knockdown of PVT1 suppressed proliferation and induced apoptosis of HCC cells}

To investigate the biological roles of PVT1 in HCC cells, we transfected Hep G2 and BEL-7402 cell lines with PVT1 shRNA or shRNA scramble vectors to knockdown the expression of PVT1. The transfection efficiency was examined by qRT-PCR. Compared with the cells transfected with shRNA scrambles, the expression of PVT1 had a significant downregulation by about $80 \%$ in Hep G2 cell line and by about 70\% in BEL-7402 cell line after $48 \mathrm{~h}$ transfection with PVT1 shRNAs (Fig. $2 \mathrm{~A}$ ). The effects of PVT1 on cell proliferation and apoptosis were investigated by CCK-8 assay and flow cytometry, respectively. As shown in

Fig. 1. Expression of PVT1 was upregulated in HCC tissues and cell lines. (A) The expression of PVT1 in 47 pairs of HCC tissues and normal tissues was examined by qRT-RCR and normalized to GAPDH expression. (B) The expression of PVT1 in 6 HCC cell lines SK-HEP-1, Hep G2, SMMC-7721, BEL-7402, Hep3B2.1-7, QGY-7703X4 and normal human hepatic cell line L-02 was measured by qRT-RCR. ${ }^{* *} \mathrm{P}<0.01,{ }^{* * *} \mathrm{P}<0.001$.

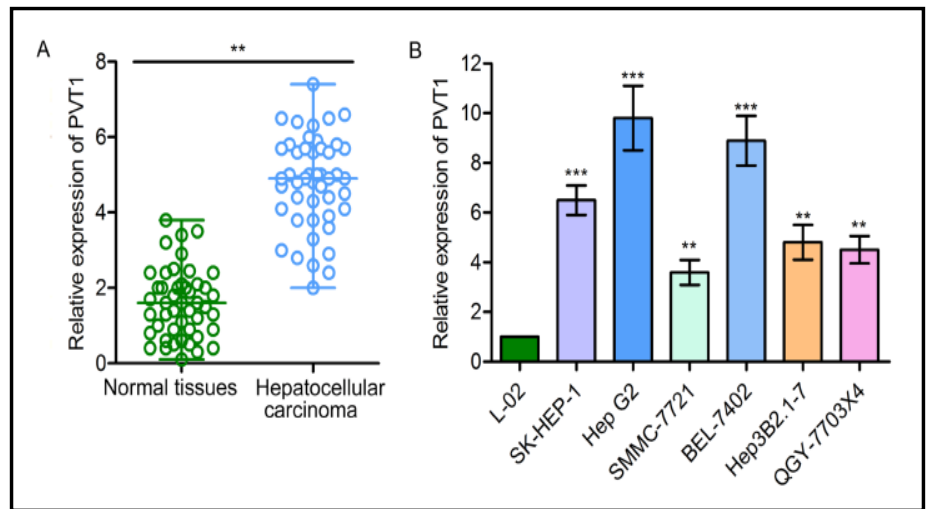


Fig. $2 \mathrm{~B}$ and $\mathrm{C}$, the cell proliferation was significantly suppressed at $72 \mathrm{~h}$ and $96 \mathrm{~h}$ posttransfection with PVT1 shRNAs in both Hep G2 and BEL-7402 cell lines. As shown in Fig. $2 \mathrm{D}$ and E, the cell apoptosis rate had an obvious increase in PVT1 shRNA-transfected Hep G2 and BEL-7402 cell lines. To further confirm the effects of PVT1 on the proliferation and apoptosis in HCC cells, we checked the protein levels of two proliferation-associated markers Ki67 and PCAN, and two apoptosis-related protein cleaved-caspase- 3 and cleaved-caspase-9 by Western blot assay. As shown in Fig. 2 F-I, both in Hep G2 and BEL-7402 cell lines, the protein expression of Ki67 and PCAN had a marked down-regulation in PVT1 shRNA group as compared with shRNA scramble group. Meanwhile, PVT1 shRNA treatment significantly promoted the protein levels of cleaved-caspase- 3 and cleaved-caspase- 9 . These data indicate

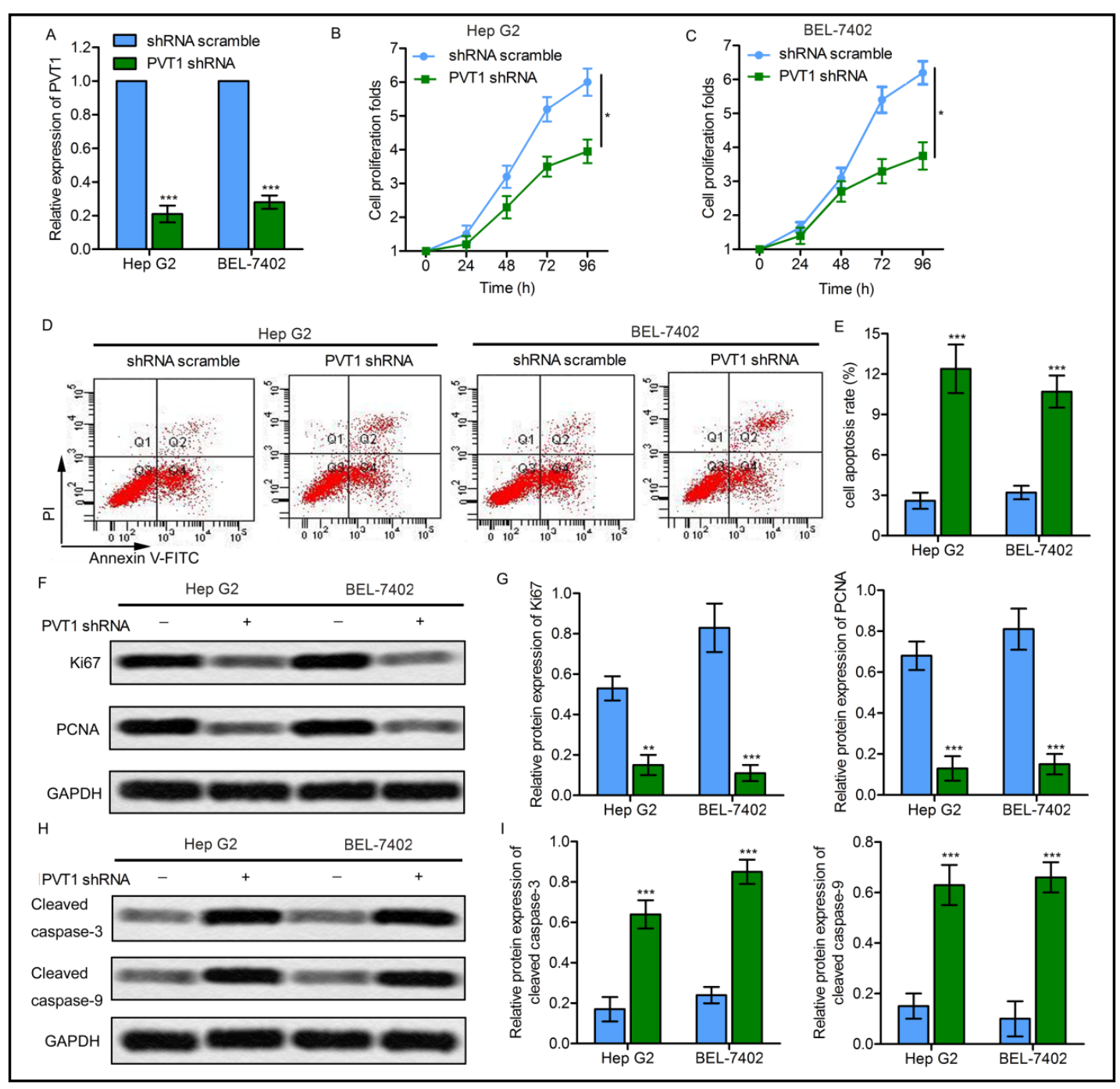

Fig. 2. Knockdown of PVT1 suppressed proliferation and induced apoptosis of HCC cells. Hep G2 and BEL-7402 cell lines were transfected with PVT1 shRNA or shRNA scramble vectors, respectively. (A) The expression of PVT1 was examined by qRT-RCR. (B and C) The cell proliferation was measured by CCK-8 assay at $24 \mathrm{~h}, 48 \mathrm{~h}, 72 \mathrm{~h}, 96 \mathrm{~h}$ post-transfection. (D and E) The cell apoptosis was detected by flow cytometry assay, and the relative apoptosis rate was shown in histogram. (F and G) The protein expression of Ki67 and PCNA was examined by Western blot assay, and the relative protein expression was shown in histogram normalized to GAPDH expression. (H and I) The protein expression of cleaved-caspase-3 and cleavedcaspase- 9 was examined by Western blot assay, and the relative protein expression was shown in histogram normalized to GAPDH expression. ${ }^{*} \mathrm{P}<0.05,{ }^{* *} \mathrm{P}<0.01,{ }^{* * *} \mathrm{P}<0.001$.

\section{KARGER}


that PVT1 knockdown suppresses proliferation and induces apoptosis of HCC cells in vitro, suggesting that PVT1 may be an oncogene in HCC.

\section{Knockdown of PVT1 inhibited migration and invasion of HCC cells}

To further investigate the biological effects of PVT1 on the migration and invasion of HCC cells, we performed wound-healing assay and Transwell assay, respectively. The results in Hep G2 cell line were consistent with that in BEL-7402 cell line. As shown in Fig. 3 A and $B$, the wound-healing ability in PVT1 shRNA group was significantly reduced as compared with that in shRNA scramble group. And knockdown of PVT1 by PVT1 shRNA induced less invasion cells than shRNA scramble treatment (Fig. $3 \mathrm{C}$ and D). Moreover, we measured the protein expression of three migration and invasion-related molecules, VEGF, MMP-9 and MMP-14, by Western blot assay. As shown in Fig. $3 \mathrm{E}$ and F, the protein expression levels of VEGF, MMP-9 and MMP-14 in PVT1 shRNA group were significantly reduced than that in shRNA scramble group. We further found that PVT1 knockdown also markedly decreased the expression of VEGFR1 and VEGFR2 (Fig. 4A-C). Furthermore, we analyzed the protein markers of epithelial-mesenchymal transition (EMT), and Fig. 4D-F showed that compared with shRNA scramble group, the expression of E-cadherin was upregulated while the expression of N-cadherin and Vimentin was downregulated in the PVT1 shRNA group. Taken together, these data show that PVT1 knockdown inhibits migration, invasion and EMT of HCC cells in vitro, further confirming that PVT1 is deeply involved in the progression of HCC.

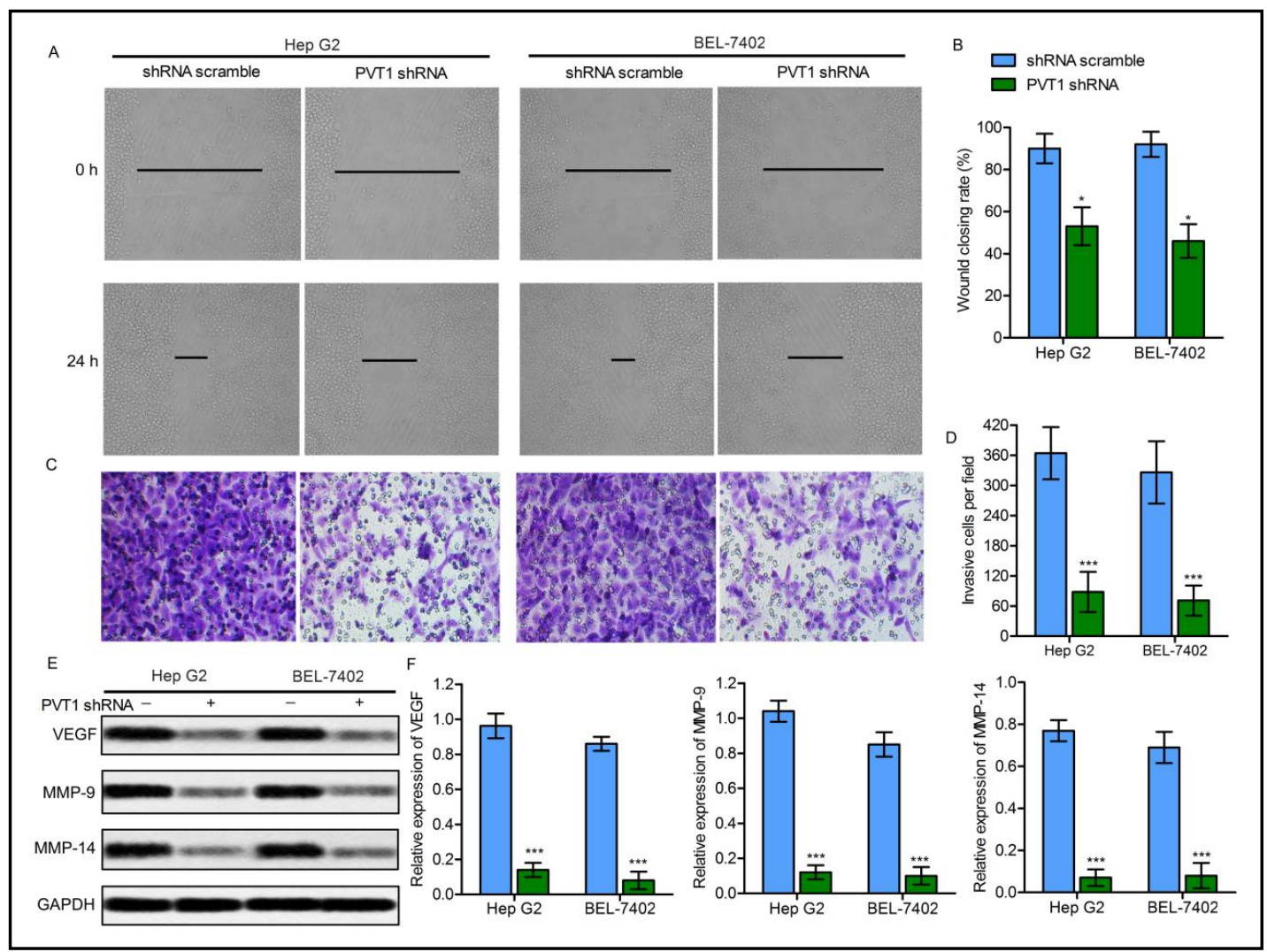

Fig. 3. Knockdown of PVT1 inhibited migration and invasion of HCC cells. (A and B) The ability of cell migration was examined by wound-healing assay, and the relative migration rate was shown in histogram. ( $C$ and D) The ability of cell invasion was examined by Transwell assay, and the relative invasion rate was shown in histogram. (E and F) The protein expression of VEGF, MMP-9 and MMP-14 was examined by Western blot assay, and the relative protein expression was shown in histogram normalized to GAPDH expression. ${ }^{*} \mathrm{P}<0.05,{ }^{* * *} \mathrm{P}<0.001$. 


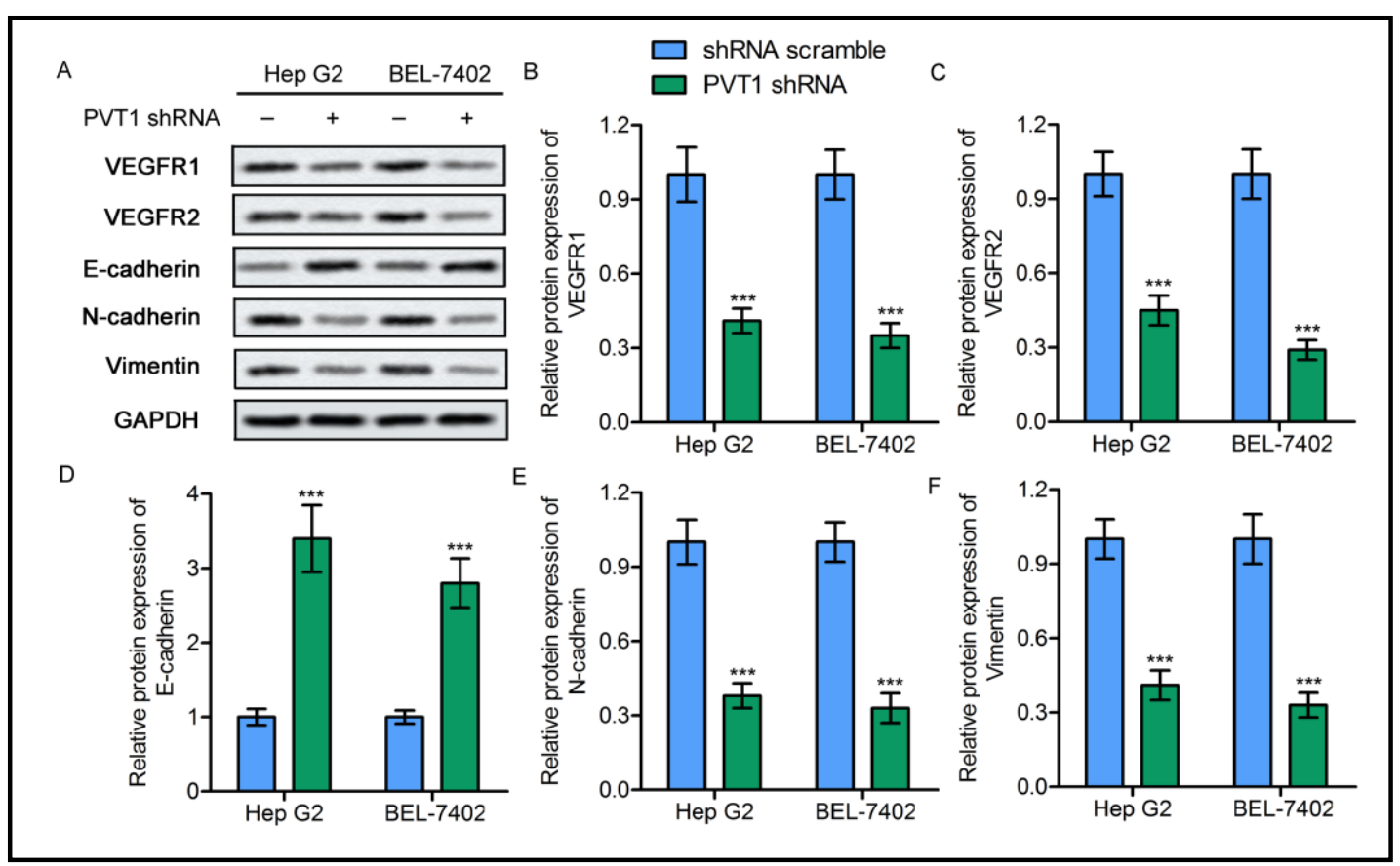

Fig. 4. Knockdown of PVT1 regulated the expression of VEGF receptors and EMT markers in HCC cells. (A) The protein expression of VEGFR1, VEGFR2, E-cadherin, N-cadherin and Vimentin was examined by Western blot assay. The relative protein expression of (B) VEGFR1, (C) VEGFR2, (D) E-cadherin, (E) N-cadherin and (F) Vimentin was shown in histogram normalized to GAPDH expression. ${ }^{* * *} \mathrm{P}<0.001$.

\section{PVT1 directly targeted miR-150}

Increasing evidences have revealed that IncRNAs contain sequences that complementary to miRNAs and could directly or indirectly regulate the expression and activity of miRNAs. We had predicted the miRNA target sites in PVT1 by bioinformatics prediction, and miR150 was investigated in the following experiments, which has been reported to be closely associated with the development of HCC. Firstly, we measured the expression of miR-150 in HCC tissues and normal tissues, as well as 6 HCC cell lines and L-02 cell line, respectively. As shown in Fig. 5A and B, qRT-PCR results showed that the expression of miR-150 was significantly down-regulated in HCC tissues as compared with that in the normal tissues. Consistent with that, the expression of miR-150 in the 6 HCC cell lines was markedly downregulated, especially in Hep G2 and BEL-7402 cell lines. The above data showed that there was a reverse relationship between the expression of PVT1 and miR-150. We further transfected Hep G2 and BEL-7402 cell lines with PVT1 shRNA vectors or the combination of PVT1 shRNA vectors and miR-150 inhibitors. The expression of miR-150 in the cells transfected with PVT1 shRNA vectors was found to be significantly up-regulated as compared with that in shRNA scramble vectors transfected cells. And compared with PVT1 shRNA + inhibitor-NC group, miR-150 expression was markedly down-regulated by the co-transfection of PVT1 shRNA vectors and miR-150 inhibitors (Fig. $5 \mathrm{C}$ and D). These results suggest that PVT1 may negatively regulate the expression of miR-150. Moreover, we confirmed the direct target relationship between PVT1 and miR-150 by dual luciferase reporter assay. We predicted two binding sites of miR-150 in PVT1, and we cloned them into psiCkeck2 vector, named pPVT11 and pPVT1-2 (Fig. 5E). Hep G2 and BEL-7402 cells were co-transfected with miRNAs (miR150 mimic, mimic-NC, miR-150 mutant) and pPVT1-1 or pPVT1-2. As shown in Fig. 5F and G, compared with mimic-NC transfection, miR-150 mimic transfection obviously decreased the luciferase activities of pPVT1-1 or pPVT1-2 dose-dependently, while there were no effects on the luciferase activities by miR-150 mutant transfection. These results indicate that PVT1directly targets miR-150 to regulate its expression. 


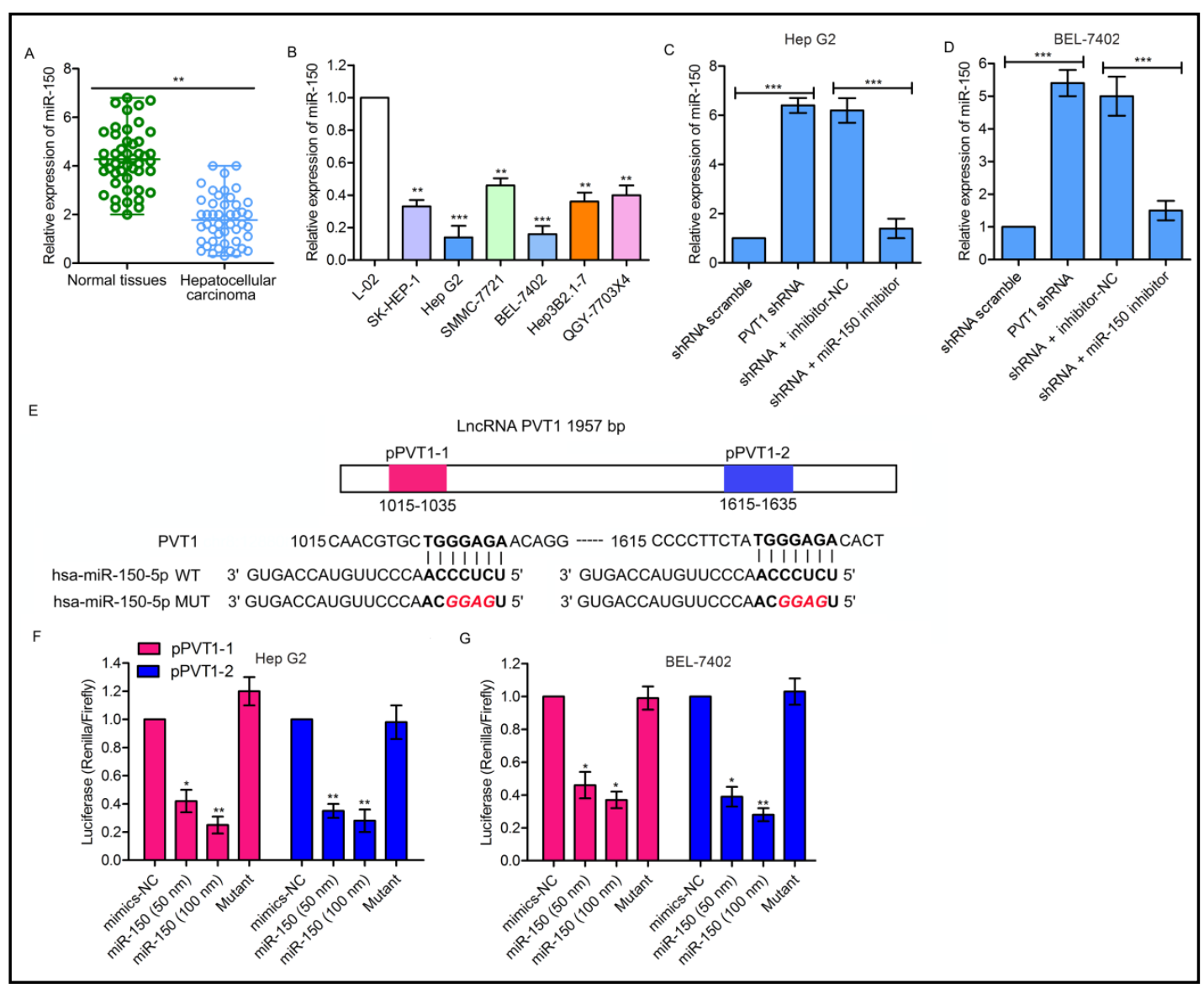

Fig. 5. PVT1 directly targeted miR-150 to regulate its expression. (A) The expression of miR-150 in 47 pairs of HCC tissues and normal tissues was examined by qRT-RCR and normalized to U6. (B) The expression of miR-150 in SK-HEP-1, Hep G2, SMMC-7721, BEL-7402, Hep3B2.1-7, QGY-7703X4 and L-02 cells were examined by qRT-RCR. (C and D) Hep G2 and BEL-7402 cell lines were transfected with PVT1 shRNA vectors or the combination of PVT1 shRNA vectors and miR-150 inhibitors. The expression of miR-150 was measured by qRT-PCR. (E) The putative target sequences of miR-150 in PVT1 were cloned into psiCkeck2 vector, and named as pPVT1-1 and pPVT1-2. The red word means the mutant area of miR-150. (F and G) Hep G2 and BEL-7402 cells were co-transfected with miRNAs (miR-150 mimic, mimic-NC, miR-150 mutant) and pPVT1-1 or pPVT1-2, and the luciferase activities were determined by dual luciferase reporter assay. ${ }^{*} \mathrm{P}<0.05,{ }^{* * *} \mathrm{P}<0.001$.

\section{PVT1 up-regulated the expression of HIG2 via targeting miR-150}

It is well known that miRNAs play biological roles by targeting the 3'-UTR of target genes. We found HIG2 was one target of miR-150 by bioinformatics prediction. We firstly measured the expression of HIG2 in HCC tissues and 6 HCC cell lines by qRT-PCR and Western blot assay, and its expression was found to be significantly increased (Fig. 6A-C). The alignment of miR-150 with 3'-UTR of HIG2 was shown in Fig. 6D. We then confirmed the direct interaction between miR-150 and 3'-UTR of HIG2 by dual luciferase reporter assay. Transfection of miR-150 mimic reduced the luciferase activities of pHIG2 dose-dependently, while there were no effects on the luciferase activities by miR-150 mutant transfection (Fig. 6E). These results indicate that miR-150 directly targets 3'-UTR of HIG2 to regulate its expression. To further support the expression of HIG2 was regulated by PVT1-miR-150 signaling, we transfected Hep G2 and BEL-7402 cell lines with PVT1 shRNA vectors or the combination of PVT1 shRNA vectors and miR-150 inhibitors. As shown in Fig. 6F and G, compared with shRNA scramble group, the mRNA and protein expression of HIG2 had a significant reduction after PVT1 shRNA transfection, which was reversed by the transfection 


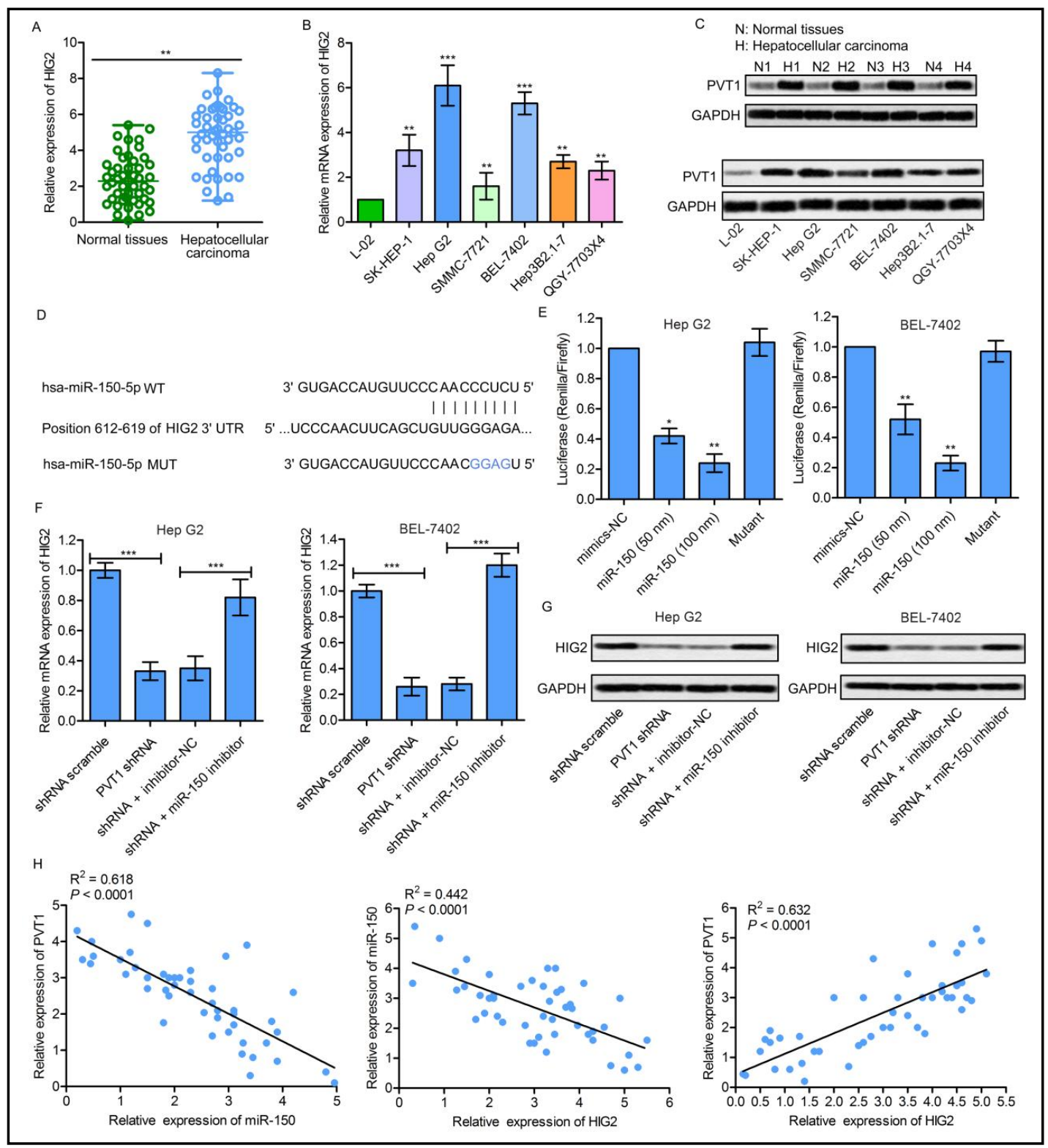

Fig. 6. PVT1 up-regulated the expression of HIG2 via down-regulating miR-150. (A) The expression of HIG2 in 47 pairs of HCC tissues and normal tissues was examined by qRT-RCR and normalized to GAPDH. (B) The expression of HIG2 in SK-HEP-1, Hep G2, SMMC-7721, BEL-7402, Hep3B2.1-7, QGY-7703X4 and L-02 cells were examined by qRT-RCR. (C) The expression of HIG2 in 4 pairs of HCC tissues and normal tissues, and HCC cell lines was examined by Western blot. (D) The putative target sequences of miR-150 in 3'-UTR of HIG2 were cloned into psiCkeck2 vector, and named as pHIG2. The blue word means the mutant area of miR150. (E) Hep G2 and BEL-7402 cells were co-transfected with miRNAs (miR-150 mimic, mimic-NC, miR-150 mutant) and pHIG2, and the luciferase activities were determined by dual luciferase reporter assay. (F and G) Hep G2 and BEL-7402 cell lines were transfected with PVT1 shRNA vectors or the combination of PVT1 shRNA vectors and miR-150 inhibitors. The expression of HIG2 was measured by qRT-PCR and Western blot assay. $(\mathrm{H})$ The negatively correlation between PVT1 and miR-150 expression, the negatively correlation between miR-150 and HIG2 expression, and the positive correlation between PVT1 and HIG2 expression in HCC tissues were shown in scatter diagram, respectively. ${ }^{*} \mathrm{P}<0.05,{ }^{* *} \mathrm{P}<0.01,{ }^{* * *} \mathrm{P}<0.001$. 
with combination of PVT1 shRNA vectors and miR-150 inhibitors. In addition, we found that there was a negative regulationship between the expression of PVT1 and miR-150, as well as between the expression of miR-150 and HIG2 in HCC tissues. Meanwhile, there was a positive relationship between the expression of PVT1 and HIG2 (Fig. 6H). These data show that PVT1could up-regulate the expression of HIG2 via targeting miR-150, suggesting that PVT1/miR-150/HIG2 axis may be an important signaling involved in the progression of HCC.

PVT1/miR-150 axis contributed to cell viability, apoptosis and motility of HCC

In the previous results, PVT1/miR-150/HIG2 axis has been shown that may be associated with the development of HCC. To determine whether the biological function of PVT1 in HCC was mediated by miR-150, we inhibited the expression of miR-150 by transfected with miR-150 inhibitors in Hep G2 cell line that PVT1 expression was suppressed. And then we measured cell viability, cell apoptosis, migration and invasion. As shown in Fig. 7A-D, PVT1 shRNAs vectors transfection-induced effects on those parameters in Hep G2 cells were consistent with the previous data, which were partly abolished by the inhibition of miR-150. In addition, we detected the protein expression of Ki67, PCNA, cleaved-caspase-3, cleavedcaspase-9, VEGF and MMP-9, and found that miR-150 inhibition rescued PVT1 shRNAs vectors transfection-induced altered expression of those proteins in Hep G2 cells (Fig. 7E-J). These results suggest that the effects of PVT1 on the cell viability, apoptosis and motility of HCC were mediated by miR-150.

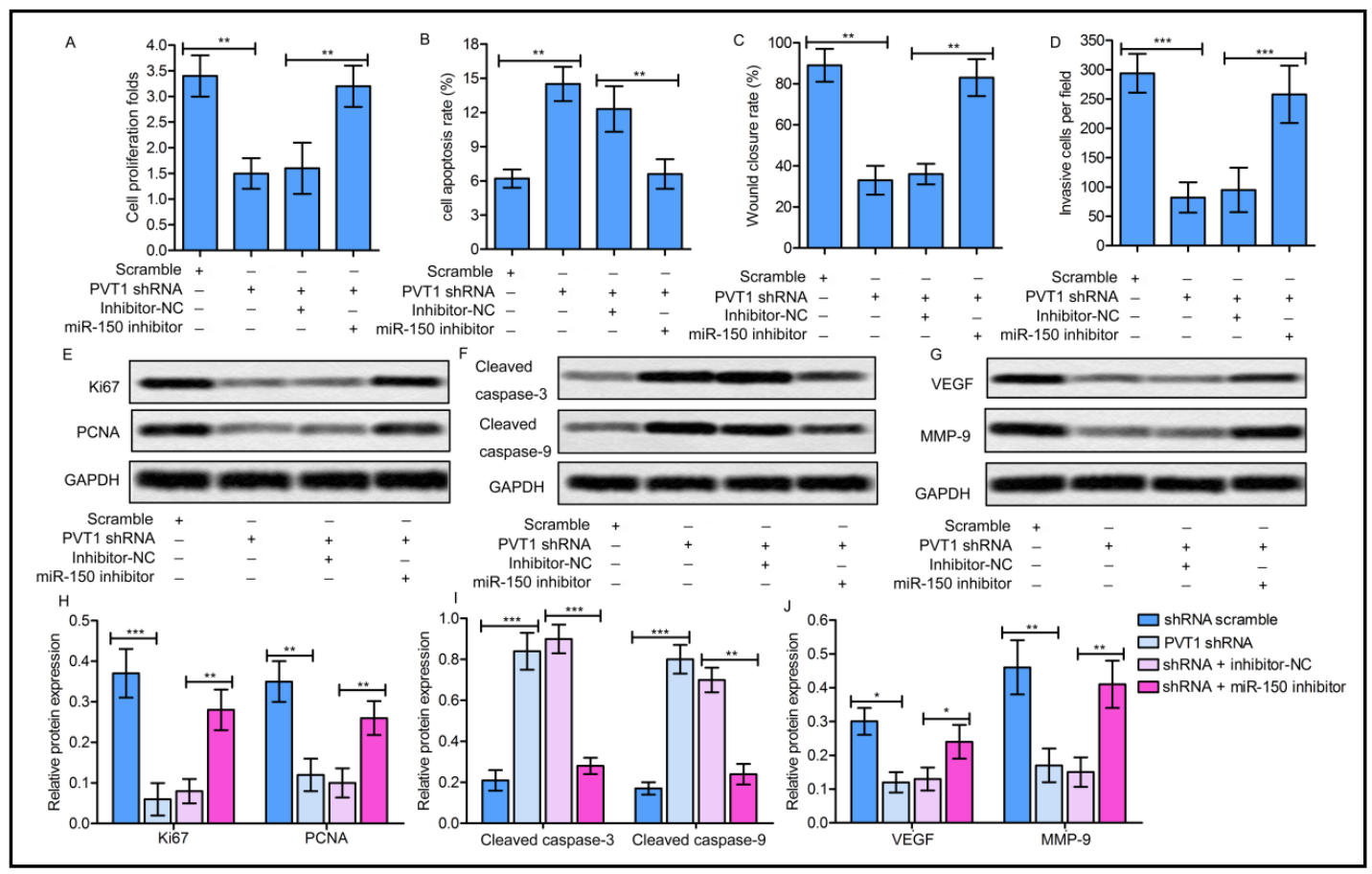

Fig. 7. PVT1/miR-150 axis contributed to regulate cell viability, apoptosis and motility of Hep G2 cells. Hep G2 cells were transfected with PVT1 shRNA vectors or the combination of PVT1 shRNA vectors and miR150 inhibitors. (A) The cell proliferation was measured by CCK-8 assay. (B) The cell apoptosis was detected by flow cytometry assay. (C) The ability of cell migration was examined by wound-healing assay. (D) The ability of cell invasion was examined by Transwell assay. The protein expression of Ki67 and PCNA (E), cleaved-caspase-3 and cleaved-caspase-9 (F), VEGF and MMP-9 (G) was examined by Western blot assay. The relative protein expression of Ki67 and PCNA (H), cleaved-caspase-3 and cleaved-caspase-9 (I), VEGF and MMP-9 (J) was shown in histogram. ${ }^{*} \mathrm{P}<0.05$, ${ }^{* *} \mathrm{P}<0.01,{ }^{* * *} \mathrm{P}<0.001$. 


\section{Cellular Physiology Cell Physiol Biochem 2018;49:1403-1419 \begin{tabular}{l|l} 
DOI: 10.1159/000493445 & $\begin{array}{l}\text { O 2018 The Author(s). Published by S. Karger AG, Basel } \\
\text { www.karger.com/cpb }\end{array}$
\end{tabular}

\section{PVT1/miR-150 axis modulated IRE/IRP regulatory system and cellular iron uptake}

HIG2, also known as HILPDA (hypoxia inducible lipid droplet associated), was identified to be involved in the regulation of several processes in diseases, such as proliferation, migration, apoptosis, lipid metabolism and iron metabolism [8, 20-22]. Iron metabolism disorder has been found in many cancer cells including HCC. We speculated that whether PVT1/miR-150/HIG2 axis was involved in regulating iron homeostasis in HCC. It is well known that the maintenance of iron homeostasis is mainly regulated by several key components, including cytoplasmic iron regulatory proteins (IRP1 and IRP2), transferrin receptor (TfR1), and ferritins. IRPs, as iron-sensing proteins, could bind iron-responsive elements (IREs) of target mRNAs to control the expression of IRP-dependent genes. Among them, TfR1 and ferritins are two important iron-related proteins that inversely regulated by IRPs. To verify our speculation, we detected the protein expression of IRP1, IRP2, TfR1 and ferritin light chain (FTL) in Hep G2 cells. As shown in Fig. 8A and B, the expression levels of IRP1 and IRP2 in PVT1 shRNA group were significantly down-regulated as compared with that in shRNA scramble group. However, the down-regulation of IRP1 and IRP2 induced by PVT1 shRNA transfection were rescued by miR-150 inhibition. Furthermore, the expression level of TfR1 had an obvious reduction in PVT1 shRNA group, and the reduction was abolished by miR150 inhibitor transfection. Meanwhile, the enhanced expression of FTL induced by PVT1 inhibition was significantly suppressed by miR-150 inhibitor (Fig. 8C and D). And then, we detected the cellular iron uptake level, and the result was shown in Fig. 8E and F. Compare with shRNA scramble group, the iron uptake level was markedly inhibited in PVT1 shRNA group, which was elevated when miR-150 inhibitors were co-transfected with PVT1 shRNA vectors. Taken together, these results suggest that PVT1 may effect IRE/IRP regulatory system and cellular iron uptake by regulating miR-150/HIG2 axis.

Fig. 8. PVT1/miR-150 axis modulated IRE/IRP regulatory system and cellular iron uptake in Hep G2 cells. (A) The protein expression of IRP1 and IRP2 was measured by Western blot assay. (B) The relative protein expression of IRP1 and IRP2 was shown in histogram. (C) The protein expression of TfR1 and FTL was measured by Western blot assay. (D) The relative protein expression of TfR1 and FTL was shown in histogram. (E and F) The cellular iron uptake was detected by quantitative colorimetric iron assay. ${ }^{* *} \mathrm{P}<0.01,{ }^{* * *} \mathrm{P}<0.001$.

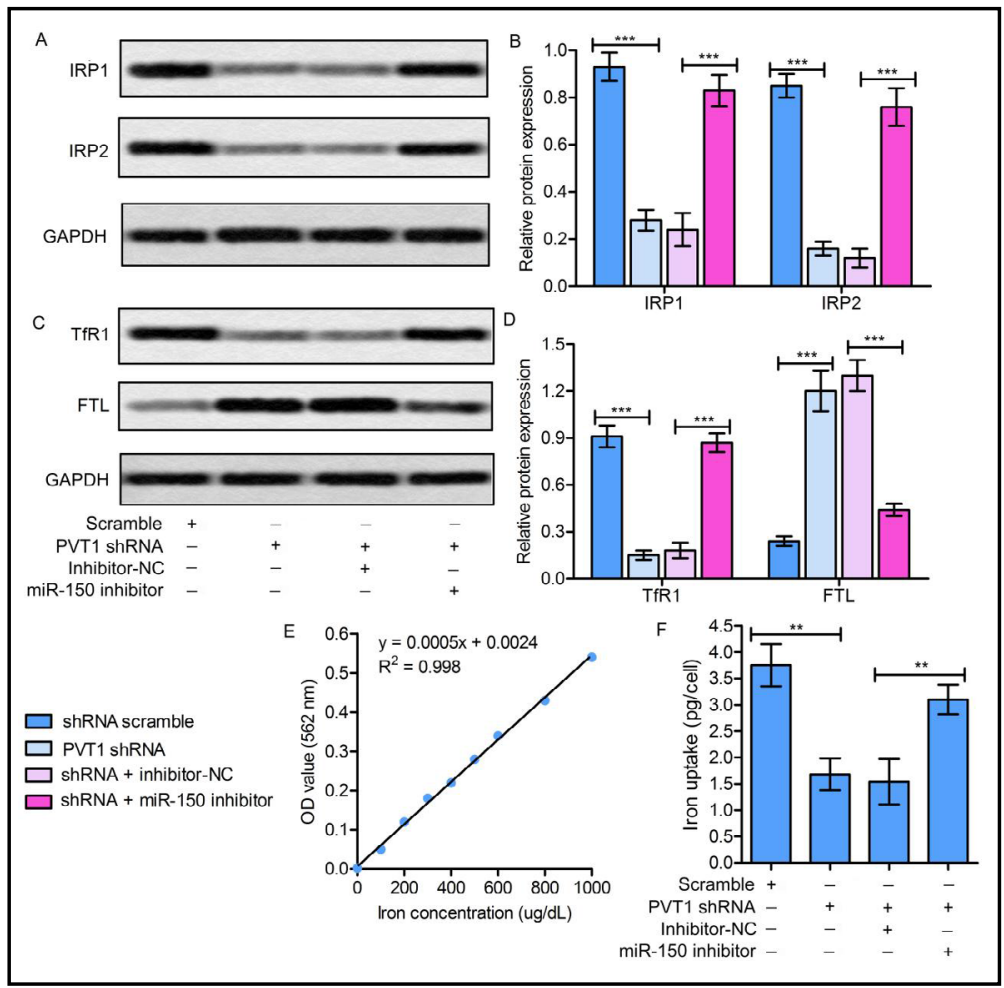




\section{Cellular Physiology Cell Physiol Biochem 2018;49:1403-1419 \begin{tabular}{ll|l} 
DOI: 10.1159/000493445 & $\begin{array}{l}\text { O } 2018 \text { The Author(s). Published by S. Karger AG, Basel } \\
\text { www.karger.com/cpb }\end{array}$ \\
\hline and Biochemistry
\end{tabular}

PVT1 knockdown suppressed tumor growth and iron metabolism disorder in vivo

To further determine the effects of PVT1 on tumorigenesis in vivo, we injected Hep G2 cells that had been stably transfected with PVT1 shRNA or shRNA scramble vectors subcutaneously into nude mice. Tumor volumes were measured every 5 days until the 30th day following cells injection. Five representative tumors from each group at 30 th day were photographed and shown in Fig. 9A, and mice injected with PVT1 shRNA-transfected cells showed smaller tumor volume than that injected with shRNA scramble-transfected cells. As shown in Fig. 9B and C, the tumor of PVT1 shRNA group showed decreased growth potential with increased survival rate compared to the shRNA scramble group. We further performed TUNEL assay and immunohistochemistry assay to detect the growth and apoptosis of tumor tissues from xenografts. As shown in Fig. 9D, the number of apoptotic bodies was elevated and the expression of Ki67 and MMP-9 had an obvious reduction in PVT1 shRNA tumor tissues as compared with shRNA scramble tumor tissues. In addition, we found that the expression of PVT1 and HIG2 were inhibited while the level of miR-150 was increased in PVT1

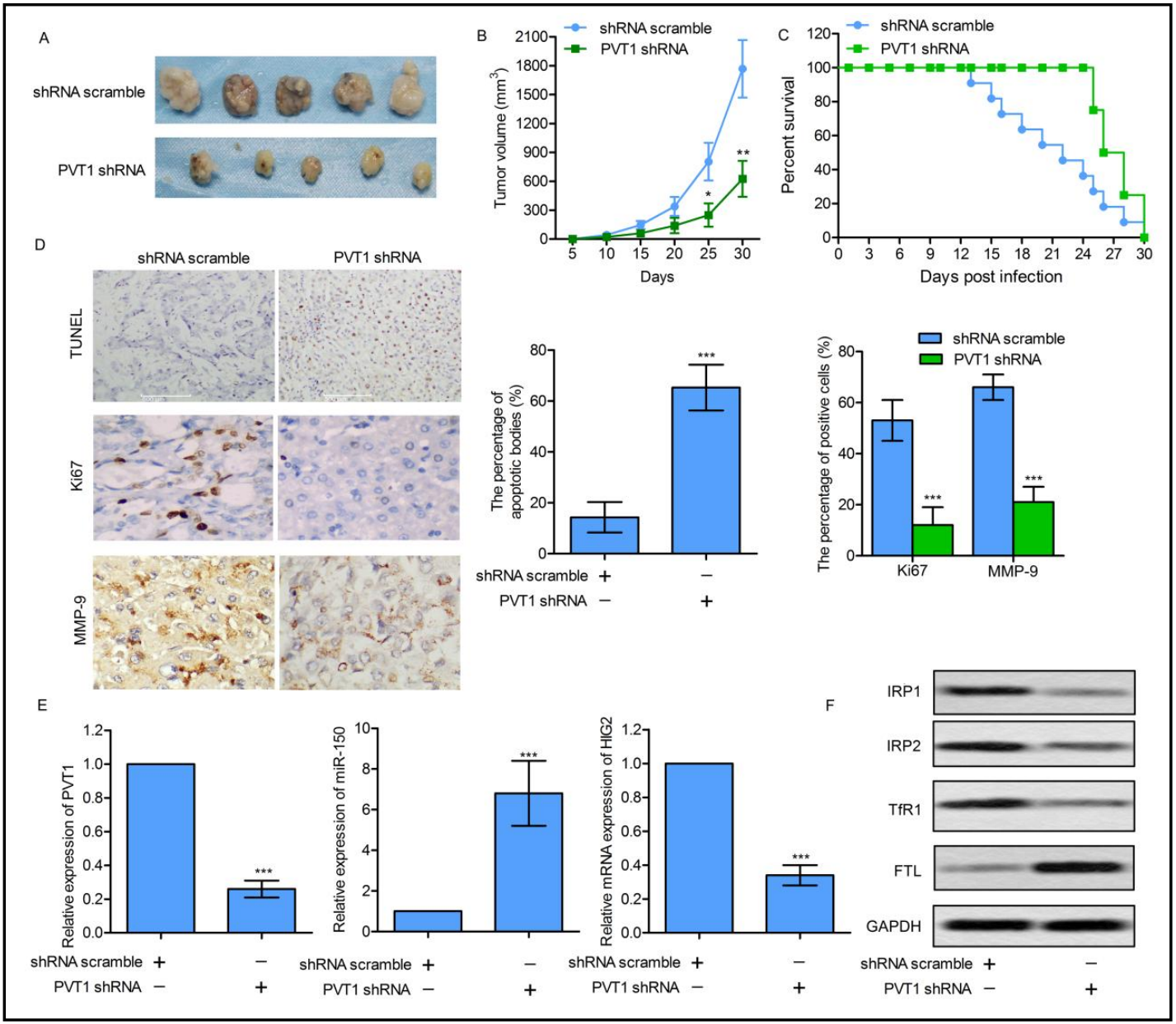

Fig. 9. PVT1 knockdown suppressed tumor growth and iron metabolism disorder in vivo. Xenograft mouse model was created by subcutaneous injection of HepG2 cells pretreated with or without PVT1 shRNA vectors to nude mouse. (A) Five primary tumors from each group were photographed after sacrifice at 30th day. (B) Tumor growth curves in two groups were shown every 5 days until the 30th day following cells injection. (C) The percentage of survival rate in each group was detected every other day. (D) The number of apoptotic bodies was measured by TUNEL assay. The expression of Ki67 and MMP-9 in primary tumor tissues was visualized by immunohistochemistry (400x). (E) The expression of PVT1, miR-150, and in primary tumor tissues was measured by qRT-PCR. (F) The expression of IRP1, IRP2, TfR1 and FTL in primary tumor tissues was measured by Western blot. ${ }^{*} \mathrm{P}<0.05,{ }^{* *} \mathrm{P}<0.01,{ }^{* * *} \mathrm{P}<0.001$. 


\section{Cellular Physiology Cell Physiol Biochem 2018;49:1403-1419 \\ \begin{tabular}{l|l} 
DOI: 10.1159/000493445 & and Biochemistry \\
Published online: 13 September, 2018 & $\begin{array}{l}\text { O } 2018 \text { The Author(s). Published by S. Karger AG, Basel } \\
\text { www.karger.com/cpb }\end{array}$
\end{tabular} \\ Xu et al.: PVT1/miR-150/HIG2 Axis Regulates HCC}

shRNA tumor tissues, which was consistent with the in vitro data (Fig. 9E). Furthermore, the expression of IRP, IRP2 and TfR1 was significantly down-regulated, while the expression of FTL showed an obvious up-regulation in PVT1 shRNA tumor tissues as compared with shRNA scramble tumor tissues (Fig. 9F). These in vivo results confirmed that PVT1 played a crucial role on regulating tumor growth and iron metabolism disorder in HCC, which may be associated with the modulation of miR-150/HIG2 signaling.

\section{Discussion}

LncRNAs have been found acting as miRNA sponges or miRNA inhibitors, which interact with miRNAs and play crucial roles in human carcinogenesis through modulating the expression of miRNA target genes 23. In the present study, we investigated the roles of PVT1 in HCC and investigated the underlying molecular mechanisms.

Firstly, we found that PVT1 expression was up-regulated in HCC tissues. To identify the biological function of PVT1 in HCC, we measured cell proliferation, cell apoptosis, migration and invasion, and EMT in vitro by loss-of-function experiments. The results demonstrated that PVT1 knockdown could suppress proliferation, migration, invasion, EMT, and induce apoptosis of HCC cells in vitro, suggesting that PVT1 act as an oncogene in HCC, which was be consistent with previous studies $[14,15]$.

Although PVT1 has been suggested to act as an oncogene in HCC, the underlying mechanisms participating in tumorigenesis still remain unknown. Wang et al. [24] have shown that the up-regulated IncRNA-urothelial carcinoma-associated 1 (UCA1) was closely associated with the progression of HCC by downregulating miR-216b expression and activating FGFR1/ERK signaling pathway. So we hypothesized that the function of PVT1 in HCC was also in part mediated by miRNAs. Recently, Yu et al. [25] has revealed that serum miR-150 level is significantly reduced in HCC patients, and miR-150 can serve as a noninvasive biomarker for the diagnosis and prognosis of HCC patients. Sun et al. [16] has reported that miR-150 down-regulation is significantly associated with a poor prognosis for HCC patients, and enforced expression of miR-150 suppresses cell proliferation and metastasis in vitro and in vivo by inhibiting the GAB-ERK axis. Combined these, miR-150 may function as a tumor suppressor in HCC. Therefore, we measured the expression of miR-150 in HCC tissues and cell lines, and confirmed that the expression of miR-150 was significantly down-regulated. We further showed that PVT1 knockdown significantly up-regulated the expression of miR-150. Furthermore, a predicted target relationship between PVT1 and miR-150 was confirmed by luciferase assay. Meanwhile, we studied whether the biological function of PVT1 in HCC cells was mediated by miR-150. MiR-150 inhibition could partly reverse the effects of PVT1 knockdown in HCC cells in vitro. Taken together, these data are consistent with our hypothesis, demonstrating that PVT1 may function as an oncogene in HCC by inhibiting miR-150 expression.

To investigate whether PVT1-induced miR-150 suppression led to an expression change of its potential target genes, we focused on HIG2 for further studies. Emerging studies have revealed that HIG2 is a potential diagnostic marker and therapy target for several cancers, such as colorectal cancer 20 , glioma 8 , renal cell carcinoma 26 and uterine cancer 27 . We found the expression of HIG2 had an obvious increase in HCC tissues. And then the expression of HIG2 was found to be significantly decreased by the transfection of PVT1 shRNA vectors in vitro, which was reversed by the co- transfection with miR-150 inhibitor, suggesting that PVT1/miR-150/HIG2 axis may be an important signaling involved in the progression of HCC.

Hypoxic microenvironment is a hallmark for various tumors including HCC [28, 29]. The genes that are critical in cell survival, cell proliferation, angiogenesis and iron metabolism in tumor cells were aberrantly expressed in response to hypoxia [30, 31]. Cellular Iron homeostasis is critical for growth and survival, and its dysregulation can cause growth arrest, apoptosis, excess free radicals [32, 33]. Hypoxia-induced iron metabolism disorder in HCC has been revealed in many investigations 34. Given that HIG2 is a hypoxia-induced 


\section{Cellular Physiology Cell Physiol Biochem 2018;49:1403-1419 \begin{tabular}{l|l} 
DOI: $10.1159 / 000493445$ & $\begin{array}{l}\text { O 2018 The Author(s). Published by S. Karger AG, Basel } \\
\text { www.karger.com/cpb }\end{array}$ \\
\hline
\end{tabular} \\ Xu et al.: PVT1/miR-150/HIG2 Axis Regulates HCC}

gene, we speculated that whether PVT1/miR-150/HIG2 axis was involved in regulating iron homeostasis in HCC. Through detecting the expression of iron homeostasis-related proteins and measuring the cellular iron uptake level, we found that PVT1 may regulate iron homeostasis in HCC through miR-150/HIG2 signaling.

To further determine whether PVT1 knockdown could suppress HCC tumorigenesis, in vivo experiments were performed. The in vivo results are consistent with the in vitro data, and suggest that PVT1 knockdown could suppresses HCC progression by regulating miR150/HIG2 axis.

\section{Conclusion}

Our present work highlights that PVT1 overexpression plays an oncogenic role by promoting progression and tumorigenesis of HCC. Knockdown of PVT1 inhibited cell proliferation, migration and invasion, promoted cell apoptosis, and suppressed iron metabolism disorder in HCC by regulating miR-150/HIG2 signaling. This study provides a new clue for understanding the pathogenesis of HCC, and indicated that PVT1/miR-150/ HIG2 axis holds great promise as therapeutic targets for HCC.

\section{Abbreviations}

lncRNA (long non-coding RNA); HCC (hepatocellular carcinoma); miR (microRNA); HIG2 (hypoxia-inducible protein 2).

\section{Acknowledgements}

The authors thank all staffs in Chengdu Military General Hospital for providing technical support and suggestions.

This study was founded by Guangzhou Provincial basic and applied basic research project (provincial natural fund) Doctor startup project (NO. 2016A030310089).

Zhongyong Jiang and Hongtao Yan conducted the main experiments; Chang Kai established the model of mouse hepatoma HepG2; Yan Peng help evaluation of pathological tissues; Ziyi Zhu help collect hepatocarcinoma tissues in hospital; Yusheng Ye help language editing of this manuscript; Jie Xiong designed this research.

\section{Disclosure Statement}

The authors declare no conflict of interests.

\section{References}

1 Jemal A, Bray F, Center MM, Ferlay J, Ward E, Forman D: Global cancer statistics. CA Cancer J Clin 2011;61:69-90.

-2 Stefano C, Inghilesi AL, Sami A, Taliani GG, Cosimo N, Fabio M: Challenges of advanced hepatocellular carcinoma. World J Gastroentero 2016;22:7645-7659.

-3 Alotaibi H, Atabey N, Diril K, Erdal E, Ozturk M: Molecular Mechanisms of Hepatocellular Carcinoma. Hepatology 2016;48:2047-2063.

4 Calvisi DF, Ladu S, Gorden A, Farina M, Lee JS, Conner EA, Schroeder IS, Factor VM, Thorgeirsson SS: Molecular pathogenesis of human hepatocellular carcinoma: Mechanistic and prognostic significance of aberrant methylation. Cancer Res 2006;66:763-763. 


\section{Cellular Physiology Cell Physiol Biochem 2018;49:1403-1419 \begin{tabular}{l|l} 
DOI: 10.1159/000493445 & $\begin{array}{l}\text { O 2018 The Author(s). Published by S. Karger AG, Basel } \\
\text { www.karger.com/cpb }\end{array}$ \\
\hline
\end{tabular} \\ Xu et al.: PVT1/miR-150/HIG2 Axis Regulates HCC}

5 Wurmbach E, Chen YB, Khitrov G, Zhang W, Roayaie S, Schwartz M, Fiel I, Thung S, Mazzaferro V, Bruix J: Genome-wide molecular profiles of HCV-induced dysplasia and hepatocellular carcinoma. Hepatology 2007;45:938-947.

6 Yang G, Lu X, Yuan L: LncRNA: a link between RNA and cancer. Biochimica Et Biophysica Acta 2014;1839:1097.

7 Rupaimoole R, Calin GA, Lopez-Berestein G, Sood AK: miRNA Deregulation in Cancer Cells and the Tumor Microenvironment. Cancer Discov 2016;6:1-11.

-8 Li SP, Xu HX, Yu Y, He JD, Wang Z, Xu YJ, Wang CY, Zhang HM, Zhang RX, Zhang JJ, Yao Z, Shen ZY: Lncrna hulc enhances epithelial-mesenchymal transition to promote tumorigenesis and metastasis of hepatocellular carcinoma via the mir-200a-3p/zeb1 signaling pathway. Oncotarget 2016;7:42431-42446.

-9 Chen CL, Tseng YW, Wu JC, Chen GY, Lin KC, Hwang SM, Hu YC: Suppression of hepatocellular carcinoma by baculovirus-mediated expression of long non-coding RNA PTENP1 and MicroRNA regulation. Biomaterials 2015;44:71.

10 Kong R, Zhang EB, Yin DD, You LH, Xu TP, Chen WM, Xia R, Wan L, Sun M, Wang ZX: Long noncoding RNA PVT1 indicates a poor prognosis of gastric cancer and promotes cell proliferation through epigenetically regulating $\mathrm{p} 15$ and p16 Mol Cancer 2015;14:82.

11 Chen X, Gao G, Liu S, Yu L, Yan D, Yao X, Sun W, Han D, Dong H: Long Noncoding RNA PVT1 as a Novel Diagnostic Biomarker and Therapeutic Target for Melanoma. Biomed Res Int 2017;2017:7038579.

12 Zhou Q Chen J, Feng J, Wang J: Long noncoding RNA PVT1 modulates thyroid cancer cell proliferation by recruiting EZH2 and regulating thyroid-stimulating hormone receptor (TSHR). Tumor Biol 2016;37:3105.

13 Wan L, Sun M, Liu GJ, Wei CC, Zhang EB, Kong R, Xu TP, Huang MD, Wang ZX: Long non-coding RNA PVT1 promotes non-small cell lung cancer cell proliferation through epigenetically regulating LATS2 expression. Mol Cancer Ther 2016;15:1082.

-14 Wang F, Yuan JH, Wang SB, Yang F, Yuan SX, Ye C, Yang N, Zhou WP, Li WL, Li W, Sun SH: Oncofetal long noncoding RNA PVT1 promotes proliferation and stem cell-like property of hepatocellular carcinoma cells by stabilizing NOP2. Hepatology 2014;60:1278-1290.

15 Chaofeng Ding ZY, Zhen LV, Chengli DU, Heng X, Chuanhui P, Shaobing Cheng, Haiyang X, Lin Z, Jian W, Shusen Z: Long non-coding RNA PVT1 is associated with tumor progression and predicts recurrence in hepatocellular carcinoma patients. Oncol Lett 2015;9:955.

16 Sun W, Zhang Z, Wang J, Shang R, Zhou L, Wang X, Duan J, Ruan B, Gao Y, Dai B: MicroRNA-150 suppresses cell proliferation and metastasis in hepatocellular carcinoma by inhibiting the GAB1-ERK axis. Oncotarget 2016;7:11595.

17 Jin M, Yang Z, Ye W, Xu H, Hua X: MicroRNA-150 Predicts a Favorable Prognosis in Patients with Epithelial Ovarian Cancer, and Inhibits Cell Invasion and Metastasis by Suppressing Transcriptional Repressor ZEB1. Plos One 2014;9:e103965.

18 Srivastava SK, Bhardwaj A, Singh S, Arora S, Wang B, Grizzle WE, Singh AP: MicroRNA-150 directly targets MUC4 and suppresses growth and malignant behavior of pancreatic cancer cells. Carcinogenesis 2011;32:1832.

19 Wang Z, Alfred C: Tumour Cell Labelling by Magnetic Nanoparticles with Determination of Intracellular Iron Content and Spatial Distribution of the Intracellular Iron. Int J Mol Sci 2013;14:9111-9125.

-20 Kim SH, Wang D, Park YY, Katoh H, Margalit O, Sheffer M, Wu H, Holla VR, Lee JS, Dubois RN: HIG2 promotes colorectal cancer progression via hypoxia-dependent and independent pathways. Cancer Lett 2013;341:159-165.

21 Mattijssen F, Georgiadi A, Andasarie T, Szalowska E, Zota A, Kronesherzig A, Heier C, Ratman D, De BK, Qi L: Hypoxia-inducible lipid droplet-associated (HILPDA) is a novel peroxisome proliferator-activated receptor (PPAR) target involved in hepatic triglyceride secretion. J Biol Chem 2014;289:19279-19293.

22 Hagist S, Sültmann H, Millonig G, Hebling U, Kieslich D, Kuner R, Balaguer S, Seitz HK, Poustka A, Mueller $\mathrm{S}$ : In vitro-targeted gene identification in patients with hepatitis $\mathrm{C}$ using a genome-wide microarray technology. Hepatology 2009;49:378.

-23 Chang YN, Zhang K, Hu ZM, Qi HX, Shi ZM, Han XH, Han YW, Hong W: Hypoxia-regulated lncRNAs in cancer. Gene 2016;575:1.

24 Wang F, Ying HQ, He BS, Pan YQ, Deng QW, Sun HL, Chen J, Liu X, Wang SK: Upregulated lncRNA-UCA1 contributes to progression of hepatocellular carcinoma through inhibition of miR-216b and activation of FGFR1/ERK signaling pathway. Oncotarget 2015;6:7899. 


\section{Cellular Physiology Cell Physiol Biochem 2018;49:1403-1419 \begin{tabular}{ll|l} 
DOI: 10.1159/000493445 & $\begin{array}{l}\text { O 2018 The Author(s). Published by S. Karger AG, Basel } \\
\text { www.karger.com/cpb }\end{array}$ \\
\hline
\end{tabular} \\ Xu et al.: PVT1/miR-150/HIG2 Axis Regulates HCC}

25 Yu F, Lu Z, Chen B, Dong P, Zheng J: microRNA-150: a promising novel biomarker for hepatitis B virusrelated hepatocellular carcinoma. Diagn Pathol 2015;10:129.

-26 Nakamura Y, Katagiri T: Hypoxia-Inducible Protein 2 (Hig2), A Novel Therapeutic Potential Target Of Renal Cell Carcinoma (Rcc). Cancer Res 2005;65:4817-26.

-27 Nishimura S, Tsuda H, Nomura H, Kataoka F, Chiyoda T, Tanaka H, Tanaka K, Susumu N, Aoki D: Expression of hypoxia-inducible 2 (HIG2) protein in uterine cancer. Eur J Gynaecol Onc 2011;32:146-149.

-28 Brown JM: Exploiting the hypoxic cancer cell: mechanisms and therapeutic strategies. Mol Med Today 2000;6:157-162.

29 Cho Y, Cho EJ, Lee JH, Yu SJ, Kim YJ, Kim CY, Yoon JH: Hypoxia Enhances Tumor-Stroma Crosstalk that Drives the Progression of Hepatocellular Carcinoma. Digest Dis Sci 2016;61:1-10.

30 Eales KL, Hollinshead KER, Tennant DA: Hypoxia and metabolic adaptation of cancer cells. Oncogenesis 2016;5:e190.

31 Peyssonnaux C, Nizet V, Johnson RS: Role of the hypoxia inducible factors HIF in iron metabolism. Cell Cycle 2008;7:28-32.

-32 Andrews NC, Schmidt PJ: Iron homeostasis. Annu Rev Physiol 2007;69:69.

33 Zhang C, Zhang F: Iron homeostasis and tumorigenesis: molecular mechanisms and therapeutic opportunities. Protein Cell 2015;6:88-100.

-34 Tanaka H: Iron facilitator LS081 reduces hypoxia-inducible factor-1 $\alpha$ protein and functions as anticancer agent in hepatocellular carcinoma. Cancer Sci 2012;103:767-774. 